\title{
Clinical Profile of Atrial Fibrillation in a Tertiary Hospital in Central Nepal
}

Sachin Dhungel, ${ }^{1}$ Shankar Laudari ${ }^{1}$

'Department of Cardiology, College of Medical Sciences, Chitwan, Nepal.

\section{ABSTRACT}

Introduction: Atrial fibrillation is a common cardiac arrhythmia in elderly causing morbidity and mortality.

Methods: A cross-sectional descriptive study was conducted in College of Medical Sciences Teaching Hospital from August 2013 to July 2016. All in-patients diagnosed with atrial fibrillation were included.

Results: Total 205 patients were studied. There were 154 (75.1\%) nonvalvular and 51 (24.9\%) valvular causes for atrial fibrillation. Common presentations were shortness of breath 84 (41\%), palpitations $57(27.8 \%)$ and stroke 38 (24.6\%). For valvular causes, common lesion was of mitral valve $(90 \%)$. Warfarin was used in $32(62.7 \%)$ with mean INR of $2.038 \pm 0.6$. Seventeen (53.1\%) had INR below 2. In nonvalvular cases, types were paroxysmal (55.2\%), persistent (34.4\%) and permanent $(10.4 \%)$. Common risk factors were heart failure 87 (56.5\%), old age (>75 years) 66 (42.8\%), hypertension 47 $(30.5 \%)$, dilated cardiomyopathy $23(14.9 \%)$, degenerative multivalvular heart disease $23(14.9 \%)$ and ischemic heart disease (13.6\%). CHADS(2) calculated 2 or more were in 98 (63.6\%) patients. Warfarin was used in 39 (25.3\%) and aspirin was used in 103 (66.9\%) patients in CHADS(2) score 2 or more. Mean INR in nonvalvular AF was $1.5 \pm 0.4$.

Conclusions: Atrial fibrillation occurred as a result of valvular or nonvalvular origin. Common presentations were shortness of breath, palpitations and stroke. Common risk factors in nonvalvular atrial fibrillation were old age, hypertension and heart failure. Warfarin was underused in nonvalvular cases in our setting.

Keywords: Atrial fibrillation; nonvalvular; valvular; warfarin underuse.

\section{INTRODUCTION}

Atrial fibrillation (AF) is the common sustained cardiac arrhythmia in elderly people. ${ }^{1}$ It is characterised by uncontrolled atrial activation with subsequent impaired atrial mechanical functions. ${ }^{2,3}$ Valvular AF is related to rheumatic valvular heart disease (predominantly mitral stenosis) or prosthetic heart valves. ${ }^{4}$ Nonvalvular AF consisted of rhythm disturbance in absences of such conditions. $^{5}$ Anticoagulants are prescribed for all valvular $A F$ and in nonvalvular AF if CHADS(2) score is 2 or more. 6,7
The condition is also common in elderly in Nepalese population. This rhythm disturbances increase mortality and increase morbidity by precipitating heart failure (HF) and cardioembolic stroke and various thromboembolic conditions. ${ }^{8-11}$

This study was conducted to determine common clinical

Correspondence: Dr. Sachin Dhungel, Department of Cardiology, College of Medical Sciences, Chitwan, Nepal. Email: dr_ dhungel@hotmail.com, Phone: +977-9851134537. 
presentations, precipitating factors, etiological profiles and the pattern of anticoagulation for the condition in our setting.

\section{METHODS}

The study was observational, cross-sectional hospital based in College of Medical Sciences Teaching Hospital (CMSTH) from August 2013 to July 2016. All in-patients diagnosed with atrial fibrillation were included after proper written and oral consent. Ethical approval was taken from Institutional Review Committee of CMSTH. Diagnosis of atrial fibrillation was done clinically by irregularly irregular pulse and electrocardiographically as varying RR interval. History and review of old available documents were done to evaluate the types of atrial fibrillation. Echocardiography was done to measure left atrial size and to confirm etiology and distinguish the valvular and nonvalvular AF. Valvular AF was defined for rheumatic valvular heart disease or prosthetic heart valves. Nonvalvular AF consisted of other causes for atrial fibrillation. Paroxysmal AF terminated within 7 days. Persistent AF if it persisted more than 7 days and permanent AF if sustained for more than 1 year or has unsuccessful cardioversions. ${ }^{12}$ All data were tabulated in Microsoft Excel and analyzed in SPSS software version 20 .

\section{RESULTS}

Out of 205 patients, mean age was $63.95 \pm 16.5$ years. Total $105(51.2 \%)$ were male and 100 (48.8\%) were female. Overall, the common presentations were shortness of breath in $84(41 \%)$, palpitations in 57 $(27.8 \%)$, stroke in $38(24.6 \%)$, chest pain in $6(2.9 \%)$, bleeding in five $(2.4 \%)$ and abdominal pain in four $(2 \%)$.

Total 154 (75.1\%) nonvalvular atrial fibrillation cases (Table 1). Among them $89(57.8 \%)$ were male and $65(42.2 \%)$ were female. Mean age was $69.6 \pm 13.3$ years. Types of atrial fibrillation were paroxysmal 85 (55.2\%), persistent $53(34.4 \%)$ and permanent 16 $(10.4 \%)$. Common presentations were shortness of breath, palpitation and stroke (Table 2). Common risk factors were heart failure $87(56.5 \%)$, elderly age (>75years) $66(42.8 \%)$ and hypertension 47 (30.5\%) (Table 3). CHADS(2) calculated 2 or more were in $98(63.6 \%)$ patients. Warfarin was used in only 39 patients (25.3\%) and aspirin was used in 103 (66.9\%). Mean INR was $1.5 \pm 0.4$.

There were 51 (24.9\%) valvular atrial fibrillation in which 35 (68.6\%) were female and 16 (31.4\%) were male. The mean age was $46.7 \pm 12.8$ years. Common valvular lesions in valvular AF were disease of mitral valve (39 patients +7 patients of MVR/DVR;90\%) or mixed with aortic valve $24(47 \%)$. There were 19
$(37.3 \%)$ mitral stenosis with mitral regurgitation, followed by $9(17.6 \%)$ mitral stenosis with aortic regurgitation, $6(11.8 \%)$ isolated mitral regurgitation, $4(7.8 \%)$ isolated mitral stenosis, $6(11.8 \%)$ aortic and mitral regurgitation, $1(2 \%)$ aortic stenosis with mitral regurgitation and $6(11.8 \%)$ mitral stenosis with mitral regurgitation with aortic regurgitation were detected valvular lesions.

The mean atrial diameter in valvular AF by echocardiography was observed in $52.61 \pm 8 \mathrm{~mm}$ (Table 4). Warfarin was used in $32(62.7 \%)$ patients, $14(27.5 \%)$ received aspirin and $5(9 \%)$ did not receive warfarin or antiplatelets. To the patients with use of warfarin, the mean INR was $2.038 \pm 0.6,17(53.1 \%)$ had INR below 2 (Table 5).

\begin{tabular}{|c|c|c|c|}
\hline Particulars & & $\begin{array}{c}\text { Nonvalvular } \\
\text { n (\%) }\end{array}$ & $\begin{array}{c}\text { Valvular } \\
\text { n (\%) }\end{array}$ \\
\hline \multirow[t]{4}{*}{$\begin{array}{l}\text { Age(mean) } \\
\text { years }\end{array}$} & & $69.6 \pm 13.3$ & $46.7 \pm 12.8$ \\
\hline & $<65$ & $47(30.5)$ & $45(88.2)$ \\
\hline & $65-74$ & $41(26.6)$ & $5(9.8)$ \\
\hline & $>75$ & 66 (42.9) & $1(2)$ \\
\hline \multicolumn{4}{|l|}{ Gender } \\
\hline & Male & $89(57.8)$ & 16 (31.4) \\
\hline & Female & $65(45.2)$ & 35 (68.6) \\
\hline \multicolumn{4}{|l|}{ Types } \\
\hline & Paroxysmal & $85(55.2)$ & $4(7.8)$ \\
\hline & Persistent & $53(34.4)$ & $21(41.2)$ \\
\hline & Permanent & $16(10.4)$ & $26(51)$ \\
\hline
\end{tabular}

Table 2. Clinical presentations.

\begin{tabular}{|lll|}
\hline $\begin{array}{l}\text { Presentations } \\
\text { Shortness of }\end{array}$ & $\begin{array}{l}\text { Nonvalvular AF } \\
\mathbf{n}(\%)\end{array}$ & Valvular AF $\mathbf{n}(\%)$ \\
$\begin{array}{l}\text { Breath } \\
\text { Palpitation }\end{array}$ & $42(27.3)$ & $15(29.4)$ \\
Stroke & $27(17.2)$ & $11(23.1)$ \\
Bleeding & $4(2.6)$ & $1(2)$ \\
$\begin{array}{l}\text { Abdominal } \\
\text { pain }\end{array}$ & $3(1.9)$ & $1(2)$ \\
Syncope & $2(1.3)$ & $1(2)$ \\
Fatigueness & $2(1.3)$ & $1(2)$ \\
Chest pain & $6(3.9)$ & 0 \\
\hline
\end{tabular}


Table 3. Risk factors in Nonvalvular Atrial Fibrillation.

\begin{tabular}{ll|}
\hline Risk factors & $\mathbf{n}(\%)$ \\
Heart Failure & $87(56.5)$ \\
Age $\geq 75$ years & $66(42.8)$ \\
Hypertension & $47(30.5)$ \\
Dilated Cardiomyopathy & $23(14.9)$ \\
Multivalvular Heart Disease & $23(14.9)$ \\
Ischemic Heart Disease & $21(13.6)$ \\
COPD & $19(12.3)$ \\
Atrial Septal Defect & $6(3.9)$ \\
Hyperthyroidism & $3(1.9)$ \\
Lung Cancer & $2(1.3)$ \\
Chronic Kidney Disease & $2(1.3)$ \\
Wolf Parkinson Heart Syndrome & $2(1.3)$ \\
Pericardial effusion & $2(1.3)$ \\
Mitral Valve Prolapse & $1(0.6)$ \\
Alcoholism & $1(0.6)$ \\
\hline
\end{tabular}

Table 4. Echocardiographic left atrial dimension in patients with atrial fibrillation.

\begin{tabular}{|c|c|c|c|}
\hline Particulars & & $\begin{array}{l}\text { Nonvalvular AF } \\
\text { n (\%) }\end{array}$ & $\begin{array}{l}\text { Valvular } \\
\text { AF n (\%) }\end{array}$ \\
\hline \multicolumn{4}{|c|}{$\begin{array}{l}\text { Left atrial dimension } \\
(\mathrm{mm})\end{array}$} \\
\hline & Mean & $43.88 \pm 6.08$ & $52.6 \pm 8$ \\
\hline & $<40$ & $65(42.2)$ & 7 (13.7) \\
\hline & $40-50$ & $70(45.5)$ & 19 (37.3) \\
\hline & $>50$ & $19(12.3)$ & 25 (49) \\
\hline
\end{tabular}

Table 5. Use of warfarin in atrial fibrillation.

\begin{tabular}{|llll|}
\hline Particulars & & $\begin{array}{l}\text { Nonvalvular } \\
\text { AF } \mathbf{n}(\%)\end{array}$ & $\begin{array}{l}\text { Valvular AF } \\
\mathbf{n}(\%)\end{array}$ \\
Aspirin use & & $103(66.9)$ & $14(27.5)$ \\
Warfarin use & & $39(25.3)$ & $32(62.7)$ \\
INR & Mean & $1.5 \pm 0.4$ & $2.0 \pm 0.6$ \\
& $1-1.5$ & $22(53.7)$ & $7(13.7)$ \\
& $1.6-2$ & $15(36.6)$ & $10(19.6)$ \\
& $\geq 2$ & $4(9.8)$ & $15(46.9)$ \\
\hline
\end{tabular}

\section{DISCUSSION}

The atrial fibrillation is common in the elderly people particular above 60 years. ${ }^{13}$ The mean age of $63.95 \pm 16.5$ years in our study is similar to age in other contemporary studies. ${ }^{8,14}$ The mean ages for the valvular and nonvalvular AF differed by 26 years. This difference in the ages owes to high prevalence of rheumatic heart disease in younger population. Such high prevalence of rheumatic heart disease in young population ranging from 20 to 30 has been described by Sharma. ${ }^{9}$ In study by Bhardwaj which had 60 percentage of rheumatic heart disease the mean age is similar to valvular $A F$ population in our study. ${ }^{14}$ In a study of nonvalvular AF by Boriani, the mean age was 71 years. ${ }^{15}$

Male had similar incidence of atrial fibrillation as female population. However in nonvalvular AF, male had 1.3 times and in valvular AF, female had 2.1 times more prevalence. The prevalence of mitral stenosis is more common in female as of different literature. ${ }^{16}$ This gender dependent difference in AF is unclear. It has been hypothesised that men have higher number of repolarizing ion channel subunits which in turn accelerate atrial depolarization, shortens atrial refractoriness and favours re-entry. Also the greater left atrial dimension in males could have promoted AF maintenance. ${ }^{17}$

Permanent atrial fibrillation was common in valvular rheumatic $(51 \%)$ while the paroxysmal variant was more common in the nonvalvular cases (55.2\%). In nonvalvular AF patients with age less than 65 , the prevalence of paroxysmal AF nearly doubled than combined persistent and persistent AF. After age 75, the combined persistent and permanent AF exceeded the prevalence of paroxysmal variant (PAF). This is because younger patients at initial diagnosis and the patients with atrial arrhythmia during follow-up were more likely to have experienced progression of paroxysmal to persistent or permanent AF. Considering the longer duration from the first diagnosis of PAF and in view of the fact that younger patients are associated with higher chances to make more substrates that might be an arrhythmogenic foci, the age at diagnosis of PAF might be a good correlate to predict AF progression. ${ }^{18}$

Valvular heart disease has been found to increase the risk of AF by 1.8 and 3.4 fold in men and women respectively. ${ }^{19}$ Even the aortic valve diseases the AV prevail around $9.1 \%$ to $33.4 \%$ depending on stages. ${ }^{19,20}$ Regarding rheumatic valvular disease in this study mitral valve were affected in $90 \%$ either as isolated stenosis $(7.8 \%)$, stenosis with regurgitation $(37.3 \%)$ or combined with aortic valve disease 24 (47\%). The distribution of the valvular lesion is similar to that of the distribution by Bhardwaj. ${ }^{14}$ The increase in incidence of atrial fibrillation in combined rheumatic MS and MR $(52 \%)$ followed by isolated MS (29\%) and then by isolated MR (16\%) have been described. ${ }^{21}$

RHD particularly mitral stenosis causes left atrial enlargement and atrial remodelling and in turn causes structural conduction abnormalities. The mean $\mathrm{M}$ mode left atrial dimension is more by $9.8 \mathrm{~mm}$ in valvular AF compared to nonvalvular AF. Studies have shown 
association between $M$ mode anteroposterior LA diameter and the risk for new onset AF. Every $5 \mathrm{~mm}$ increase in LA diameter increased the development of AF by $39 \% .21,22$

In both valvular and nonvalvular AF shortness of breath, palpitation, stroke and thromboembolism were the commonest symptomatic presentations. In nonvalvular $\mathrm{AF}$, heart failure occured in $56.5 \%$ patients and stroke in $17.2 \%$ patients. Similar findings were from Dhakal et $\mathrm{al}^{10}$ and Patel et al. ${ }^{23}$ However, Gautam et al, had palpitation as the most common presenting symptoms followed by dyspnea. ${ }^{8}$

Heart failure (42.9\%) was the commonest overall presentations. Whether $\mathrm{AF}$ precipitates $\mathrm{HF}$ or $\mathrm{HF}$ precipitates $A F$ is not clear. In the presence of $H F$, the risk of AF increases 4.5 to 5.9 fold. Thence, $\mathrm{HF}$ is a stronger risk than advanced age, valvular heart disease, hypertension, diabetes mellitus or prior myocardial infarction. Overall patients with heart failure develop $\mathrm{AF}$ at a rate of 6 to $8 \%$ per year and $A F$ is present in $>15 \%$ of heart failure patients. ${ }^{1,17}$

Stroke and thromboemolism occurred in $24.6 \%$ of overall population which is comparable to $15-23 \%$ described by other authors. ${ }^{8,9,11}$ CHADS(2) has been considered as a high risk of stroke. ${ }^{24}$ The score is $>1$ in 98 (63.6\%) patients of nonvalvular origin. Apart from age hypertension was the most common risk factor among the patients. 97 (63\%) patients had hypertension. This high prevalence in atrial fibrillation has been comparable to other authors. ${ }^{25}$ Anticoagulants are recommended in CHADS $>1 .{ }^{26}$ In our study, warfarin was used only in $39(25.3 \%)$ nonvalvular AF and 32 (62.7\%) valvular AF patients. High use of warfarin in valvular AF cases is because of inclusion of younger and compliant patients after counselling, MVR and post PTMC cases. Wang et al, described such underuse $(16.2 \%)$ of anticoagulant in nonvalvular AF. ${ }^{27}$ Cohen et al, has described old age, language difficulties, insufficient doctor's alertness to warfarin's benefit and patient disability as reluctance to treat patients with warfarin. ${ }^{28}$

Eleven patients gave history of minor bleeding with use of warfarin. Two had hemorrhagic strokes and 1 patient died. One had rectus sheath hematoma. Warfarin was underused in our population mainly due to fear of increased risk of bleeding. The frequency of warfarin induced bleeding is 15 to $20 \%$ per year, with life threatening or fatal bleeding rates as high as 1 to $3 \%$ per year has been described. ${ }^{29}$

Aspirin was used in 103 (66.9\%) nonvalvular AF meeting CHADS(2) criteria. Even in valvular AF, 14 $(27.5 \%)$ used aspirin instead of warfarin. Use of aspirin alone in nonvalvular AF has found to reduce the risk of non-disabling stroke. ${ }^{30}$ Use of aspirin and clopidogrel in patients in whom warfarin cannot be added reduced the combined end point of first occurrence of stroke, non central nervous systemic embolism, myocardial infarction and vascular death. ${ }^{31}$ However warfarin has been superior to combination of aspirin and clopidogrel. ${ }^{32}$ Newer anticoagulants have been developed for use in nonvalvular atrial fibrillation. ${ }^{33-35}$ These anticoagulants are not available in our country.

Prospective follow-up study would have given more insights of the various complications owing to the disease and medications used. Another separate study for valvular and nonvalvular atrial fibrillation can make the study statistically clear. More extensive study regarding complications owing to use of warfarin can help in identifying the hinderance and underuse of warfarin in our population.

\section{CONCLUSIONS}

Atrial fibrillation occurred as result of valvular or nonvalvular origin. Common risk factors were old age, hypertension and heart failure. Common presentations were shortness of breath, palpitations and stroke. Warfarin is underused in atrial fibrillation in our setting.

\section{ACKNOWLEDGMENTS}

We acknowledge the support and guidance from Prof. Dr. G. Subramaniyam, Prof. P.V.S. Rana, Prof. B.S. Patowary, Prof. Dr. S. Guru Prasad, Prof. Dr. Sanjib K Sharma, Prof. Dr. Mani Gautam, Dr. Samir Gautam, Associate Prof. Dr. Laxman Dubey, Dr. Tej Bahadur Gurung, Dr. Pradeep Jung Shah, Dr. Rajesh Panjiyar, Dr. Madhu Gupta, Dr. Jigyasa Subedi, Dr. Binit Aryal, Dr. Mandip Dhungel and Indra Dumre.

\section{Conflict of Interest: None.}

\section{REFERENCES}

1. Kannel WB, Abbott RD, Savage DD, McNamara PM. Epidemiologic features of chronic atrial fibrillation: the Framingham study. N Engl J Med. 1982;306(17):1018-22. [PubMed $\mid \underline{\text { DOI }]}$
2. Gutierrez C, Blanchard DG. Diagnosis and treatment of atrial fibrillation. Am Fam Physician. 2016;94(6):442-52. [PubMed]

3. Allessie M, Ausma J, Schotten U. Electrical, contractile and structural remodeling during atrial fibrillation. Cardiovasc Res. 2002;54(2):230-46. [PubMed] 
4. Camm AJ, Lip GY, De Caterina R, Savelieva I, Atar D, Hohnloser SH, et al. 2012 focused update of the ESC guidelines for the management of atrial fibrillation: an update of the 2010 ESC guidelines for the management of atrial fibrillation. Developed with the special contribution of the European Heart Rhythm Association. Eur Heart J. 2012;33(21):2719-47. [ubMed | DOI]

5. Fuster V, Ryden LE, Cannom DS, Crijns HJ, Curtis AB, Ellenbogen KA, et al. Guidelines for the management of patients with atrial fibrillation. Executive summary. Revista espanola de cardiologia. 2006;59(12):1329. [PubMed | DOI]

6. Lane DA, Lip GY. Use of the CHA(2)DS(2)-VASc and HAS-BLED scores to aid decision making for thromboprophylaxis in nonvalvular atrial fibrillation. Circulation. 2012;126(7):860-5. [ [ PubMed | DOI]

7. Fauchier L, Philippart R, Clementy N, Bourguignon T, Angoulvant D, Ivanes F, et al. How to define valvular atrial fibrillation? Arch Cardiovasc Dis. 2015;108(10):530-9. [PubMed $\mid \underline{\text { DOI] }}$

8. Gautam MP GS, GuruPrasad S. Subramanyam G, Ghimire U. A study of the clinical profile of atrial fibrillation in a tertiary care superspeciality referral center in central Nepal. Journal of College of Medical Sciences-Nepal. 2012;8:9-16. [DOI]

9. Sharma SK, Verma SH. A clinical evaluation of atrial fibrillation in RHD. J Asssoc Physicians India. 2015;63:22-5. [PubMed]

10. Dhakal M, Dhakal OP, Nandy P. Epidemiology and clinical presentation of patients with atrial fibrillation from a tertiary care hospital of East Sikkim: an observational study. Journal of Evolution of Medical and Dental Sciences. 2013;2(20):3554-60. [DOI]

11. Maskey A, Parajuli M, Kohli SC. A study of risk factors of stroke in patients admitted in Manipal Teaching Hospital Pokhara.' Kathmandu Univ Med J (KUMJ). 2011;36:244-7. [Full Text]

12. January CT, Wann LS, Alpert JS, Calkins H, Cigarroa JE, Cleveland JC, Jr., et al. 2014 AHA/ ACC/HRS guideline for the management of patients with atrial fibrillation: executive summary: a report of the American College of Cardiology/ American Heart Association Task Force on practice guidelines and the Heart Rhythm Society. Circulation. 2014;130(23):2071-104. [PubMed | DOI]

13. Zoni-Berisso M, Lercari F, Carazza T, Domenicucci S. Epidemiology of atrial fibrillation: European perspective. J Clin Epidemiol. 2014;6:213-20. [라Med | DOI]

14. Bhardwaj R. Atrial fibrillation in a tertiary care institutea prospective study. Indian Heart J. 2012;64:476-8. [Full Text $\mid \underline{\text { DOI] }}$

15. Boriani G, Cimaglia P, Fantecchi E, Mantovani V, Ziacchi M, Valzania C, et al. Non valvular atrial fibrillation: potential clinical implications of the heterozenous definitions used in trials on new oral anticoagulants. J Cardiovasc Med. 2015;16:491-6. [Full Text | DOI]

16. Benjamin EJ, Levy D, Vaziri SM, D'Agostino RB, Belanger AJ, Wolf PA. Independent risk factors for atrial fibrillation in a population-based cohort. The Framingham Heart Study. JAMA. 1994;271(11):840-4. [PubMed]
17. Andrade J, Khairy P, Dobrev D, Nattel S. The clinical profile and pathophysiology of atrial fibrillation: relationships among clinical features, epidemiology, and mechanisms. Circ Res. 2014;114(9):1453-68. [PubMed]

18. Im S, II, Chun KJ, Park S-J, Park K-M, Kim JS, On YK. Long-term Prognosis of Paroxysmal Atrial Fibrillation and Predictors for Progression to Persistnt or Chronic Atrial Fibrillation in the Korean Population. J Korean Med Sci. 2015;30(7):895-902. [Full Text | DOI]

19. Greve AM, Gerdts E, Boman K, Gohlke-Baerwolf C, Rossebø $A B$, Nienaber $C A$, et al. Prognostic importance of atrial fibrillation in asymptomatic aortic stenosis: the Simvastatin and Ezetimibe in Aortic Stenosis study. Int J Cardio. 2013;166(1):72-6. [PubMed | DOI]

20. Stortecky S, Buellesfeld L, Wenaweser P, Heg D, Pilgrim T, Khattab AA, et al. Atrial Fibrillation and Aortic Stenosis. Circ Cardiovasc Interv. 2013;6(1):77-84. [․ㅏbMed | DOI]

21. Diker E, Aydogdu S, Ozdemir M, Kural T, Polat K, Cehreli $\mathrm{S}$, et al. Prevalence and predictors of atrial fibrillation in rheumatic valvular heart disease. Am J Cardiol. 1996;77(1):96-8. [PubMed]

22. Vaziri SM, Larson MG, Benjamin EJ, Levy D. Echocardiographic predictors of nonrheumatic atrial fibrillation. The Framingham Heart Study. Circulation. 1994;89(2):724-30. [PubMed]

23. Patel D, Chavda A, Goswami I. Clinical study and etiological evaluation of atrial fibrillation at tertiary care hospital, Jamnagar, Gujarat, India. Int J Recent Sci Res. 2012;1:122-4. [DOI]

24. Gage BF, van Walraven C, Pearce L, Hart RG, Koudstaal PJ, Boode BS, et al. Selecting patients with atrial fibrillation for anticoagulation: stroke risk stratification in patients taking aspirin. Circulation. 2004;110(16):2287-92. [PubMed | DOI]

25. Manolis AJ, Rosei EA, Coca A, Cifkova R, Erdine SE, Kjeldsen $\mathrm{S}$, et al. Hypertension and atrial fibrillation: diagnostic approach, prevention and treatment. Position paper of the Working Group 'Hypertension Arrhythmias and Thrombosis' of the European Society of Hypertension. J Hypertens. 2012;30(2):239-52. [․ubMed | DOI]

26. Solomon MD, Ullal AJ, Hoang DD, Freeman JV, Heidenreich $\mathrm{P}$, Turakhia MP. Cost-effectiveness of pharmacologic and invasive therapies for stroke prophylaxis in atrial fibrillation. J Cardiovasc Med (Hagerstown). 2012;13(2):86-96. $[\underline{\text { PubMed }} \mid \underline{\text { DOI }]}$

27. Wang C, Yang Z, Wang C, Wang Y, Zhao X, Liu L, et al. Significant underuse of warfarin in patients with nonvalvular atrial fibrillation: results from the China national stroke registry. J Stroke Cerebrovasc Dis. 2014;23(5):1157-63. [PubMed $\mid \underline{\text { DOI }]}$

28. Cohen N, Almoznino-Sarafian D, Alon I, Gorelik O, Koopfer M, Chachashvily S, et al. Warfarin for stroke prevention still underused in atrial fibrillation: patterns of omission. Stroke. 2000;31(6):1217-22. [PubMed]

29. Zareh M, Davis A, HendersonS. Reversal of warfarin-induced hemorrhage in the emergency department. West J Emerg Med. 2011;12(4):386-92. [PubMed] 
30. Hart RG, Pearce LA, Aguilar MI. Meta-analysis: antithrombotic therapy to prevent stroke in patients who have nonvalvular atrial fibrillation. Ann Intern Med. 2007;146(12):857-67. [PubMed]

31. Connolly SJ, Pogue J, Hart RG, Hohnloser SH, Pfeffer M, Chrolavicius S, et al. Effect of clopidogrel added to aspirin in patients with atrial fibrillation. $\mathrm{N}$ Eng J. Med.. 2009;360(20):2066-78. [PubMed | DOI]

32. Connolly S, Pogue J, Hart R, Pfeffer M, Hohnloser S, Chrolavicius $S$, et al. Clopidogrel plus aspirin versus oral anticoagulation for atrial fibrillation in the atrial fibrillation clopidogrel trial with irbesartan for prevention of vascular events (ACTIVE W): a randomised controlled trial. Lancet. 2006;367(9526):1903-12. [PubMed | DOI]

33. Connolly SJ, Ezekowitz MD, Yusuf S, Eikelboom J, Oldgren J, Parekh A, et al. Dabigatran versus warfarin in patients with atrial fibrillation. N Engl J Med. 2009;361(12):1139-51. [ubMed $\mid \underline{\text { DOI }]}$

34. Granger CB, Alexander JH, McMurray JJ, Lopes RD, Hylek EM, Hanna M, et al. Apixaban versus warfarin in patients with atrial fibrillation. N Engl J Med. 2011;365(11):981-92. [ $\underline{\text { PubMed }} \mid \underline{\text { DOI] }}$

35. Patel MR, Mahaffey KW, Garg J, Pan G, Singer DE, Hacke $\mathrm{W}$, et al. Rivaroxaban versus Warfarin in Nonvalvular Atrial Fibrillation. N Engl J Med. 2011;365(10):88391. $[\underline{\text { PubMed }} \mid \underline{\text { DOI }]}$ 